\title{
BMJ Open Quality Implementing primary palliative care best practices in critical care with the Care and Communication Bundle
}

\author{
Cristina Vuong, ${ }^{1}$ Sheri Kittelson, ${ }^{2}$ Lindsay McCullough, ${ }^{2}$ Yao Yingwei, ${ }^{1}$ \\ Tonja Hartjes ${ }^{1}$
}

To cite: Vuong C, Kittelson S, McCullough L, et al. Implementing primary palliative care best practices in critical care with the Care and Communication Bundle. BMJ Open Quality 2019;8:e000513. doi:10.1136/ bmjoq-2018-000513

Received 7 September 2018 Revised 11 July 2019 Accepted 20 July 2019
Check for updates

(C) Author(s) (or their employer(s)) 2019. Re-use permitted under CC BY-NC. No commercial re-use. See rights and permissions. Published by BMJ.

${ }^{1}$ University of Florida College of Nursing, Gainesville, Florida USA

${ }^{2}$ Department of Medicine, University of Florida College of Medicine, Gainesville, Florida, USA

Correspondence to Dr Cristina Vuong; cristinavuong@ufl.edu

\section{ABSTRACT}

Background Clinician-family communication is a central component of medical decision-making in the intensive care unit (ICU) and the quality of this communication has a direct impact on decisions made regarding care for patients who are critically ill.

Aim The purpose of the project was to emphasise the need for quality improvement in the medical ICU at the University of Florida Health Hospital in regard to communication between the patients, families and providers.

Method Interventions included development of a more systemic approach to primary palliative care by using the nationally recognised and published Care and Communication Bundle tool. The Bundle is a standardised clinical pathway of palliative care best practices.

Results During the project period, staff satisfaction/ engagement increased from tier 3 to tier 1 level, the medical ICU length of stay decreased from 4.97 days in fiscal year (FY) 2016 to 4.22 days in FY2017. Moreover, the number of patients discharged directly to hospice increased from 21 in FY2016 to 42 in FY2017, representing a $100 \%$ increase. Additionally, palliative care consults decreased in the medical ICU (FY2016 $=108$, FY2017=82), as a result of an increase in daily primary palliative care interventions. The findings demonstrate an improvement in outcome measures during the project.

\section{INTRODUCTION}

\section{Problem description}

According to the Centers for Disease Control and Prevention, 130.4 million visits are made annually to the emergency department, of which 12.2 million patients are admitted into the hospital and 1.5 million directly into the critical care unit. ${ }^{1}$ In relation to the complexity and/or life-threatening conditions of those admitted into the intensive care unit (ICU), whether through direct admission or transfer within the inpatient setting, the mortality rate in an adult ICU is approximately $10 \%-29 \% .^{2}$ Although goals of care and end-of-life decisions are often discussed in the ICU, there is a lack of consistency in when and how communication occurs. This can result in poor communication, fragmented care, unnecessary suffering, conflict between patients, families and medical teams, and increased patient length of stay (LOS) when treatment is not in line with the patient's goals of care.

According to the Agency for Healthcare Research and Quality (AHRQ) and the Healthcare Cost and Utilization Project, hospital admissions involving ICU services were two and a half times more costly, accounting for $\$ 281800000$ or $47 \%$ of total hospital charges. Additionally, these patients were three times more likely to experience major complications or comorbidities than those patients who did not have an ICU stay. ${ }^{3}$ Moreover, several studies have demonstrated a positive relationship between moral distress/burnout with critical care nurses and physicians, specifically in regard to end-oflife care. ${ }^{4-6}$ While significant differences in perceived levels of moral distress were found between professions and settings, the top ranked cause of distress was watching patient care suffer due to lack of provider continuity and poor communication. ${ }^{6}$

\section{Available knowledge}

In 2001, the Institute of Healthcare Improvement and the Voluntary Hospital Association (VHA) began a joint initiative towards 'bundle' care as an approach to improve critical care processes. ${ }^{7}$ Focusing specifically on areas with potential of great harm and high cost, these bundles would consist of evidence-based or best practice interventions and methods, which would individually improve care and collectively provide a standardised method for the delivery of consistent high-quality care. ${ }^{7}$ Further support for bundled care occurred in 2003 and 2004, in response to the need for improvement of quality of palliative care (PC) in critical care units. A national project was undertaken by the 'Transformation of the ICU' programme through the VHA. ${ }^{8}$ This initiative developed a PC bundle to improve and standardise clinicians' communication with patients 


\begin{tabular}{ll}
\hline Table 1 Care and Communication Bundle \\
\hline Domain & Measure \\
\hline $\begin{array}{l}\text { ICU day } 1^{*} \\
\text { Patient/family-centred } \\
\text { decision-making }\end{array}$ & $\begin{array}{l}\text { Determination of medical } \\
\text { decision-maker }\end{array}$ \\
$\begin{array}{l}\text { Patient/family-centred } \\
\text { Patient/family-centred } \\
\text { decision-making }\end{array}$ & Advance directive status \\
$\begin{array}{l}\text { Communication and } \\
\text { health literacy }\end{array}$ & Code status \\
\hline $\begin{array}{l}\text { Symptom management } \\
\text { ICU day } 3\end{array}$ & $\begin{array}{l}\text { Pain assessment and } \\
\text { management }\end{array}$ \\
$\begin{array}{l}\text { Emotional and social } \\
\text { support for patient/families } \\
\text { Spiritual support of } \\
\text { patient/families }\end{array}$ & $\begin{array}{l}\text { Social work support offered to } \\
\text { patient/family } \\
\text { ICU day } 5\end{array}$ \\
$\begin{array}{l}\text { Communication } \\
\text { offered to patient/family }\end{array}$ \\
\hline
\end{tabular}

This table shows quality measures of the Care and Communication Bundle, which are triggered based on ICU days 1, 3 and 5. These quality measures were developed based on the domains identified by the Critical Care Peer Workgroup, which identified quality indicators for end-of-life care in the ICU. ${ }^{22}$

*The day of ICU admission is considered day 0 and the following calendar day is day 1 .

ICU, intensive care unit.

and families, to reduce unmet patient/family needs and reduce 'burnout' among caregivers in ICUs. ${ }^{8}$

Additionally, the Institute of Medicine's (IOM) 'Crossing the Quality Chasm' report called for decreasing variation, increasing adherence to evidence-based guidelines, the monitoring of processes and measuring outcomes as critical for improving quality of care. ${ }^{9}$ ICU care sometimes includes conflict over goals of care between teams, patients and families. Communication can be inadequate, resulting in unmet family needs and suffering in patients and families. ${ }^{8}$ The result was the Care and Communication Bundle (CCB), which consisted of quality indicators implemented based on LOS triggers at ICU days 1, 3 and 5 (table 1).

In short, the CCB addresses basic components of communication and operationaliZes process measures. On day 1 of the ICU stay (day after ICU admission), identification of appropriate decision-maker, advance directive status, assessment and treatment of pain, and distribution of family information leaflet should occur. On day 3, social work and spiritual support are offered and on day 5 , an interdisciplinary family meeting occurs to improve communication regarding diagnoses, prognosis, and patient/family concerns and goals of treatment. Despite the fact that multiple studies ${ }^{8}{ }^{10-13}$ have shown that process measures of the CCB positively impact outcomes such as decreased LOS and improved family satisfaction and comprehension, implementation of the bundle is still inconsistent, infrequently used and/or appropriately documented in the patient chart.

The literature demonstrates the CCB as an effective strategy with positive patient/family outcomes (eg, patient/family satisfaction) by facilitating communication to discuss goals of care in a process that encourages shared decision-making. When consistently applied and monitored, family satisfaction in regard to communication and how well the healthcare team performed improved. ${ }^{11}{ }^{14-16}$ The strength of bundled care is found in its consistent approach to care of the specific patient population. Barriers to compliance exist, however interventions such as educational materials, interdisciplinary steering committee, recruitment and training of local champions within each institution, and providing learning sessions have shown to improve compliance and sustainability of the bundle. ${ }^{1718}$

Clinician-family communication is a central component of medical decision-making in the ICU and the quality of this communication has a direct bearing on decisions made regarding care for patients who are critically ill. The CCB should be used to close the gap between current knowledge of optimal care and current clinical practice, and between the care patients want and the care they receive. Previously, in the medical ICU (MICU) at the University of Florida (UF) Health Hospital, only aspects of the CCB were used, and they were inconsistently performed or documented. Additionally, there were no standardised processes for the communication between patients/families and providers.

\section{Specific aims}

The purpose of this project was to emphasise the need for quality improvement (QI) in the MICU at UF Health Hospital with regard to communication between the patients, their families and providers with the goal of developing a more systemic approach to primary PC by using the nationally recognized and published CCB tool.

\section{METHODS}

\section{Context}

A pilot study was conducted to implement the CCB at UF Health Hospital, within a 24-bed adult MICUwith all private rooms. UF Health Hospital is a level 1 trauma, academic, tertiary care and regional referral centre with 973 beds in north central Florida.

\section{Intervention}

UF Health uses the 'Plan, Do, Study, Act' (PDSA) QI methodology. The PDSA is a system-wide useful tool for documenting a test of change (Plan), carrying out the test (Do), observing and learning from the consequences (Study) and determining what modifications should be made to the test (Act). Our problem: Vizient tracks academic health system quality by a 'report card' that includes mortality, efficiency (LOS), safety, equity, 
patient centredness (Hospital Consumer Assessment of Healthcare Providers and System survey scores) and effectiveness (readmissions). UF Health received its annual rating and was rated as a three-star hospital in 2016 with opportunities for improvement in efficiency, effectiveness and patient centredness (EEPC).

The CCB pilot's objectives aligned with the institution-wide objectives (above) to improve EEPC. Hospital leadership developed EEPC committees to address specific areas for improvement and PC was identified as a key opportunity for QI. The IOM's 'Dying in America' report speaks to the national goal of addressing the lack of consistent approaches to address the palliative needs of patients with serious illness, which results in prolonged LOS and reduced patient and staff satisfaction. ${ }^{9}$ An interdisciplinary PC EEPC team was created and included administration, bedside nurses, a nurse manager, a clinical leader, PC resource nurses, physicians (interns, residents, attendings) and social workers.

The team met to develop a study charter, which included defining the problem as previously noted. The charter was presented to hospital leadership prior to implementation for approval and support of the institution-wide QI initiative. Previous PC QI work was reviewed to include the implementation of PC and Hospice in Place programmes within the neurosurgical ICU. It was noted that provider communication was inconsistent in how and when family communication occurred, as well as when advance care planning was reviewed. A literature review revealed a published best practice that was selected as a tool for this pilot. Objectives were created and local expert opinion identified the CCB as a clinical pathway to standardise the care of patients with serious illness. The committee then defined the scope of practice to the MICU and if successful, plans would be made to expand the CCB institution-wide. Customers and stakeholders were defined as patients, families, faculty, staff, hospice and leadership. Measures were identified as outlined below. PDSA cycles are described below, but to note initial cycles revealed the need to modify data collected given logistical difficulties of manual chart review for family meeting completion. Milestones with target dates were defined. Additionally, a new family information leaflet was created using a best practice published model.

\section{Study of the interventions}

To evaluate the effects of the bundle, data were retrospectively collected to compare MICU average LOS, number of PC consults, number of direct discharges to hospice, and employee engagement and satisfaction monthly from the fiscal year (FY) prior to the study (FY2016: 1 July 2015 to 30 June 2016) and compared with the FY in which the bundle was initiated (FY2017: 1 July 2016 to 30 June 2017).

The study underwent three PDSA cycles that will be described in detail below based on each cycle.

\section{PDSA cycle 1}

A multidisciplinary committee was convened to implement the bundle in the MICU. Members from the team who worked in the ICU (champion resident physician and doctorate of nurse practitioner/registered nurse) planned a series of monthly physician educational session's coinciding with the first day of the new internal medicine resident rotation. This session would serve to review the CCB information. It was identified that nursing staff would also require education on the bundle and the team created a standardised educational 20 min video educating nurses on the bundle itself to include the evidence behind its use and practical things such as where to locate and document advance directive information in the electronic medical record (EMR). This video was released to all ICU nurses via a programme called My Training during the intervention year. To further standardise the process, the CCB was added to a daily rounding goal sheet on a checklist to ensure the bundle was addressed by the rounding team as part of the standardised daily workflow. The above PDSA cycle was implementing processes and resulted in descriptive outcome data that all staff received baseline training in the bundle during the pilot year and were satisfied with their training from informal verbal feedback at monthly quality meetings. No specific outcome data were obtained, such as testing comprehension and staff satisfaction with the training. Nursing management and PC resource nurses informally reported a significant shift in the culture of the unit seeing a dramatic improvement in communication between staff and patients, mostly as a result of an increase in family meetings that were rare prior to implementation of the bundle.

\section{PDSA cycle 2}

In preparing for the first educational session, the QI team recognised that the MICU did not have a family information leaflet as described in the CCB article. The Plan was for team members to review the original article by Azoulay et al published in 2002 entitled 'Impact of a Family Information Leaflet on Effectiveness of Information Provided to Family Members of ICU Patients,' and create our own leaflet. The original study was a multicentre prospective randomised controlled trial in 34 French ICUs showing that the leaflet improved comprehension and satisfaction in families. After reviewing the article including contents of the actual information leaflet, the team created our own institution-specific family leaflet that included information on common medical terms, MICU hours, team member names and roles, and discussion of the advance directive and family meeting. After a draft was approved by the committee, it was checked for appropriate literacy level. The MICU then distributed the information leaflet to $100 \%$ of patient families on the first day of their admission to the MICU, and if they were not present during the admission process the leaflet was left at bedside. Creating 


\begin{tabular}{|c|c|c|}
\hline $\begin{array}{l}\text { Patient/Employee Satisfaction Team } \\
\text { MICU Results }\end{array}$ & $\begin{array}{l}\text { Aug } \\
2017\end{array}$ & $\begin{array}{l}\text { Nov } \\
2017\end{array}$ \\
\hline & $\mathrm{n}: 12$ & $\mathrm{n}: 18$ \\
\hline $\begin{array}{l}\text { 1.) Overall quality of nursing care delivered to you/your } \\
\text { family member while in the MICU }\end{array}$ & 4.2 & 4.9 \\
\hline $\begin{array}{l}\text { 2.) Nurses addressed you/your family member's } \\
\text { Comfort/concerns }\end{array}$ & 4.3 & 4.9 \\
\hline $\begin{array}{l}\text { 3.) Nurses/PCA's/Tech promptness in responding to } \\
\text { you/your family member's calls }\end{array}$ & 4.3 & 4.8 \\
\hline $\begin{array}{l}\text { 4.) Communication with you/your family member by } \\
\text { Physician }\end{array}$ & 3.7 & 4.4 \\
\hline 5.) Procedures were explained prior to performing them & 3.8 & 4.9 \\
\hline 6.) Staff concern for you/your family member's privacy & 4.4 & 4.9 \\
\hline $\begin{array}{l}\text { 7.) Staff's concern for you/your family member's } \\
\text { safety...hand washing, armband, call light }\end{array}$ & 4.8 & 4.9 \\
\hline 8.) Cleanliness of the unit and the room & 4.3 & 5 \\
\hline 9.) Visitation policy explained Yes/No & $\begin{array}{l}\text { No } \\
\text { result }\end{array}$ & $\begin{array}{l}94 \% \text { yes/ } \\
6 \% \text { no }\end{array}$ \\
\hline Average questions 1-8 & 4.2 & 4.8 \\
\hline
\end{tabular}

Figure 1 University of Florida (UF) Health Hospital MICU-patient/employee satisfaction survey. Using the patient/employee satisfaction survey that was already being implemented in the MICU for all patients, results from the interval period from which no family leaflet was in place to the time after implementation showed increase in survey measures including overall quality, communication, explanation of procedures and education on visitation policy. MICU, medical intensive care unit; PCA, patient care assistant.

the information leaflet was the process improvement and the outcome was $100 \%$ compliance. As part of this PDSA cycle we did not check on comprehension or satisfaction with a specific survey, as did the original large multisite study, rather we tracked patient/family satisfaction in a survey that was already being implemented for all MICU patients. Over the interval period from no leaflet to leaflet, we noted an interval increase in survey measures including overall quality, communication, explanation of procedures and education on visitation policy. This PDSA cycle was also a process measure and did not result in specific outcome data other than viewing standardised patient satisfaction scores, which were used as an indirect proxy measure of satisfaction (figure 1).

\section{PDSA cycle 3}

In the third PDSA cycle, the team recognized thelack of a standardized location for documentation of advance directives or family meeting. A side committee was formed and a new build was created in the EPIC electronic health record that allowed sharing of advance directive information, such as healthcare surrogate, to be viewed by nursing, social work and advance practice providers and physicians across care settings and admissions. Additionally, the team created a flow sheet to document a family meeting which included information such as who was present, items discussed to include prognosis, code status, advance directives and goals of care. This flow sheet information could be pulled into a note type 'team conference' and viewed by all providers on the team. The note type also included all the information necessary to bill for a Medicare Advance Care
Planning visit so that the note could be recognised by billing staff. This PDSA cycle had process measures including creating the build necessary for documentation of a family meeting, but did not include outcome measures of compliance of use which would be a future PDSA cycle.

\section{Measures}

Several measures were initially identified as metrics for collection and are described below. Advance directive completion rate and documentation of the family meeting were difficult to track and revisions were made over the course of the project during the PDSA cycles as tracking compliance was not possible due to EMR limitations for automated extraction and manual chart review was a labour-intensive process without a dedicated resource.

The advance directive completion rate was measured prior to the CCB implementation from the nursing admission paperwork in which nursing team would ask the patient and/or family if they had a completed advance directive marking 'yes/no' in the chart, and request them to bring the document if not available. Advance directive completion rates were at $30 \%$. Team members including nursing staff often were not familiar with where to obtain advance care planning documents in the EMR and how to properly document and submit patient wishes or discussions to the medical team for review. Additionally, no follow-up mechanism was in place for staff to ask families if they brought in the document. During the first PDSA cycle, teams created a process flow and educated nursing staff on the location of the advance directive in the electronic health record. A 'advance care planning' tab was created that was shared between nursing, social work and advance practice providers and physicians to document the presence of advance care planning. Moreover, obtaining advance directives and identifying legal decision-maker were added to daily rounding goal sheets as a checklist to increase completion of these measures. Social work added advance directive to their documentation flow sheet to also collect this information if not already done by nursing or medical teams. The rate of advance directive completion 'yes/no' will later be extracted using the 'healthcare directive' tab.

Family meeting in the first PDSA cycle required manual chart review with a documentation rate of zero resulting in creation of a process in EPIC to document family meeting completion as a 'yes/no' box that will be automatically extracted. Discussion revealed that meetings did in fact occur but were inconsistently documented. Family meeting 'yes/no' was added to the 'advance care planning' tab in EPIC. A mechanism for automated extraction and completion of family meetings now occurred based on LOS. This is a process measure and does not record the outcome of the meeting, quality of communication, but that communication did in fact occur. General categories of who was present and what was discussed were added to the tab (eg, code status, prognosis) and next steps were added (further discuss goals at next meeting, hospice or 
PC referral). This tab could be pulled into a team conference note and would be carried across care settings from MICU to medical surgical floors, from one admission to the next, from inpatient to outpatient and for all nursing, social work or medical providers. Family meetings were also added to daily rounding goal sheets for patients who had LOS greater than 4 days in the MICU.

MICU LOS was selected as a metric for improvement. LOS was isolated to the MICU to be certain any impact on LOS was not attributable to confounding variables such as concurrent QI initiatives. LOS was tracked using the clarity/business objects system and verified independently with the quality department analytics team. PC consults were tracked and reported by the inpatient PC team. Hospice discharges were tracked from EPIC EMR in the same way as collecting discharges that occurred specifically from the MICU to hospice. Employee engagement and satisfaction scores were obtained from the annual National Database of Nursing Quality Indicators (NDNQI) survey. MICU staff were informally interviewed on a monthly basis to see if they felt the change in outcome measures was due to the CCB intervention or other reasons. Overall, MICU management, floor social worker and unit PC resource nurses felt strongly the bundle was the key intervening impacting LOS.

Since certain measures (eg, advance directive completion, documentation of family meeting) could not be accurately collected during the pilot study, the measures included in the study were those that could be analysed (eg, MICU LOS, PC consults, discharges to hospice, and employee engagement and satisfaction).

\section{Analysis}

Descriptive statistics were used to describe MICU baseline data (FY16) and compare to postimplementation data (FY17). Data were reviewed and teams selected the median over mean to remove outliers. Additionally, data were isolated to include only the MICU. Staff satisfaction and engagement data were determined based on changes from NDNQI scores from FY16 to FY17.

\section{Patient and public involvement}

The CCB is from nationally published best practice protocol including national experts and QI hospital agencies. Prior to this QI project in the MICU at UF Health Hospital, only aspects of the CCB were used, and they were inconsistently performed or documented. Additionally, there were no standardised processes for the communication between patients/families and providers. The development of theCCB measures were created in an effort to enhance patients' priorities, experience and preferences with the goal of developing a more systematic approach with regard to communication between the patient, their families and providers.

Patients were not directly involved in the design and recruitment of this QI project. Results were disseminated at poster presentations at Patient Safety and Quality Week
Table 2 UF Health Hospital MICU-length of stay

\begin{tabular}{llll}
\hline $\begin{array}{l}\text { Patient-day } \\
\text { FY }\end{array}$ & Accounts & $\begin{array}{l}\text { Total patient- } \\
\text { days }\end{array}$ & $\begin{array}{l}\text { Average } \\
\text { LOS by } \\
\text { account }\end{array}$ \\
\hline 2016 & 1613 & 8019 & 4.97 \\
2017 & 1811 & 7637 & 4.22 \\
\hline
\end{tabular}

This table shows average LOS before and after implementation of the Care and Communication Bundle as shown by LOS in fiscal year 2016 and fiscal year 2017.

FY, fiscal year; LOS, length of stay; MICU, medical intensive care unit; UF, University of Florida.

at UF Health Hospital, College of Nursing Research Week, and presented to ICU leadership meetings.

\section{Human participants}

This study did involve human participants. Patients' aggregate data were provided by quality department including patient LOS, PC consults and direct MICU discharges to hospice. No personal identifiable information was included. Institutional Review Board approval was obtained.

\section{RESULTS}

Retrospective data were obtained from FY16 (1 July 2015 to 30 June 2016) which served as baseline data for measures prior to initiation of the bundle. The baseline data revealed that average LOS was 4.97 days which decreased to 4.22 days after implementation of the bundle for FY17 (table 2). This is a significant decrease in LOS by $15 \%$ $(\mathrm{p}<0.05)$. PC consults rate also decreased from $6.7 \%$ to $4.5 \%$ (figure 2), while the percentage of direct MICU discharge to hospice increased from $1.3 \%$ to $2.3 \%$ (figure 3).

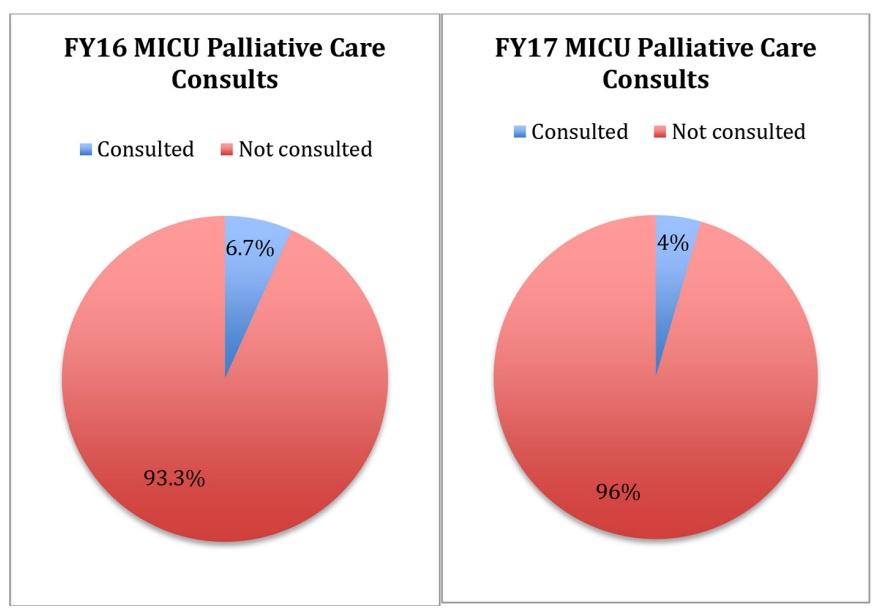

Figure 2 University of Florida (UF) Health Hospital MICUpalliative care consults. Comparison of MICU palliative care consults prior to implementation of the Care and Communication Bundle (CCB) as seen in FY16 with palliative care consults in FY17 in which the CCB was in place.

Palliative care consults rate decreased from $6.7 \%$ in FY16 to $4.5 \%$ in $\mathrm{FY} 17$. FY, fiscal year; MICU, medical intensive care unit. 


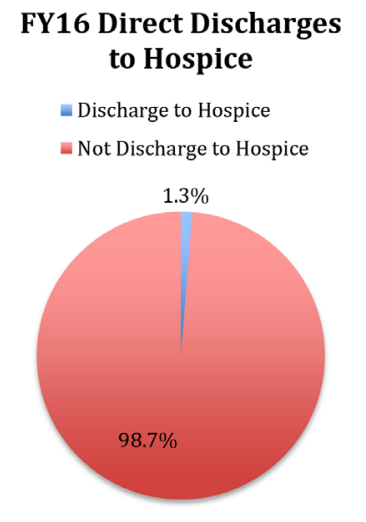

\section{FY17 Direct Discharges to Hospice}

Discharge to Hospice

- Not Discharge to Hospice



Figure 3 University of Florida (UF) Health Hospital $\mathrm{MICU}-$ direct discharge to hospice. Prior to implementation of the Care and Communication Bundle (CCB), direct discharges from the MICU to hospice for FY16 were 1.3\%. This increased to $2.3 \%$ in FY17 in which the bundle was implemented. FY, fiscal year; MICU, medical intensive care unit.

Additional results collected in the study included NDNQI scores that reflect employee engagement and satisfaction based on organisation, manager and employee satisfaction scores. In the year following CCB implementation, organisation satisfaction increased from 3.73 to 4.19 , manager satisfaction increased from 3.79 to 4.36 and employee satisfaction increased from 3.82 to 4.27 (figure 4). Moreover, the MICU scored 93\% for action planning readiness representing a high willingness to implement change. In summation, in the year following implementation of the bundle, MICU scores were placed in tier 1 category, representing the highest level of employee engagement and satisfaction. This is a significant improvement from FY16 in which the MICU scores were measured in tier 3 category.

\section{DISCUSSION}

\section{Summary}

The AHRQ identified nine evidence-based national priorities for palliative and end-of-life care with the goals of including relief of suffering, help with emotional and spiritual needs, communication about treatment and dying, and PC and hospice services. ${ }^{19}$ The CCB is consistent with these high-quality measures for PC in the ICU. The QI project revealed with the implementation of the CCB, the MICU average patient LOS reduced and the number of discharges directly to hospice increased. However, the overall number of PC consults decreased likely reflecting of overall increase in primary PC by providers within the unit, which was a primary aim for implementation of the CCB in ICUs.

\section{Limitations}

The retrospective nature of this project includes inherent limitations. Additionally, the results cannot be generalised to other populations, as it is a single-facility, single-unit

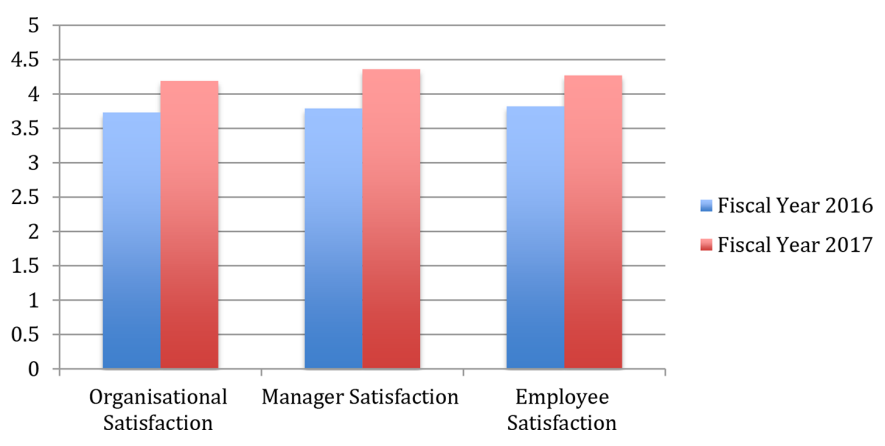

Figure 4 University of Florida (UF) Health Hospital MICU-employee engagement and satisfaction. Employee engagement and satisfaction scores are based on three domains: organisation, manager and employee satisfaction. In the year in which the bundle was in place (FY17), scores in all three domains increased in comparison to the year prior to the bundle implementation (FY16) showing an overall improvement in employee engagement and satisfaction. FY, fiscal year; MICU, medical intensive care unit.

project. Limiting factors may be the characteristics of the patient population or other unit-based changes not accounted for that may account for year-to-year changes. Use of the EMR includes limitations related to manual chart review, inaccurate or incomplete submissions and tracking of data. Further evaluation with additional PDSA cycles is needed to measure true compliance of the bundle and its documentation in EMR. Hospital-wide implementation of the bundle to all ICU units is currently underway. Further research and statistical analysis are required to determine the strength of association of these process measures to patient outcomes.

\section{CONCLUSIONS}

Clinician-family communication is a central component of medical decision-making in the ICU and the quality of this communication has a direct impact on decisions made regarding care for patients who are critically ill. The purpose of the project was to standardise the approach to primary PC in the ICU by using the nationally recognised and published CCB tool to improve the quality in the ICU and in the hospital overall. The demand for PC specialists is growing rapidly, since timely $\mathrm{PC}$ consultations have been shown to improve the quality of care, reduce overall costs and, in some populations such as outpatient lung cancer, increase longevity. ${ }^{1920}$ Given this, there is more demand for PC consultation than can be met by current supply of specialists nationally and at UF Health Hospital. This project increased primary $\mathrm{PC}$ in the intensivist teams engaging in basic PC processes such as goals of care conversations, basic symptom management, discussion of advance directives and code status. PC was consulted for the more complex cases of conflict between team members, family, uncontrolled symptoms or cases of near futility. ${ }^{21}$ 
Sustainability of the CCB will be impacted by: (1) the creation of policies and procedures related to its use, (2) intermittent evaluation of compliance-as a unit performance measure, (3) creating the CCB as a standard of care in every ICU within UF Health, (4) including education of the CCB to all new hires and new resident physicians during orientation, (5) use of EPIC EMR processes to encourage easy access to information and documentation of meetings, and (6) providers' ability to find meaningful outcomes with its utilization in relation to time, effort and potential discomfort regarding this sensitive topic.

Acknowledgements The authors thank the Center for Palliative Care Research and Education at the University of Florida for assistance in implementation of Care and Communication Bundle in the MICU at UF Health Hospital. The authors also thank the members of the interdisciplinary teams in the MICU at UF Health who have contributed to the development of the patient/family information leaflet in addition to the implementation of the Care and Communication Bundle.

Contributors CV planned and conducted the study as well as drafting of the manuscript. SK designed the study and made contributions to the drafting and revision of manuscript. LM contributed to conduction and acquisition of data as well as revision of the manuscript. YY contributed to analysis and interpretation of data. $\mathrm{TH}$ made substantial contributions to the design of the study as well as drafting, revision of manuscript and interpretation of data.

Funding The authors have not declared a specific grant for this research from any funding agency in the public, commercial or not-for-profit sectors.

Competing interests None declared.

Patient consent for publication Not required.

Ethics approval Institutional review board (IRB) approval was granted by the University of Florida (IRB201701323).

Provenance and peer review Not commissioned; externally peer reviewed.

Data availability statement All data relevant to the study are included in the article or uploaded as supplementary information.

Open access This is an open access article distributed in accordance with the Creative Commons Attribution Non Commercial (CC BY-NC 4.0) license, which permits others to distribute, remix, adapt, build upon this work non-commercially, and license their derivative works on different terms, provided the original work is properly cited, appropriate credit is given, any changes made indicated, and the use is non-commercial. See: http://creativecommons.org/licenses/by-nc/4.0/.

\section{REFERENCES}

1. Centers for Disease Control and Prevention. Emergency department visits. Available: https://www.cdc.gov/nchs/fastats/emergencydepartment.htm [Accessed 12 Dec 2017].

2. Society of Critical Care Medicine. Critical care statistics. Available: http://www.sccm.org/Communications/Pages/CriticalCareStats.aspx [Accessed 2 Jan 2018].

3. Barrett ML, Smith MW, Elixhauser A. Utilization of intensive care services, 2011. agency for healthcare research and quality. statistical
Brief:185. 185, 2014. https://hcup-us.ahrq.gov/reports/statbriefs/ sb185-Hospital-Intensive-Care-Units-2011.jsp

4. Peckham C, Medscape. Medscape National Physician Burnout \& Depression Report, 2018. Available: https://www.medscape.com/ slideshow/2018-lifestyle-burnout-depression-6009235\#1 [Accessed 1 Mar 2018].

5. Shoorideh FA, Ashktorab T, Yaghmaei F, et al. Relationship between ICU nurses' moral distress with burnout and anticipated turnover. Nurs Ethics 2015;22:64-76.

6. Whitehead PB, Herbertson RK, Hamric AB, et al. Moral distress among healthcare professionals: report of an institution-wide survey. J Nurs Scholarsh 2015;47:117-25.

7. Resar R, Griffin FA, IHI Innovation Series White Paper. Using care bundles to improve health care quality, 2012. Available: http://www. ihi.org/resources/Pages/IHIWhitePapers/UsingCareBundles.aspx [Accessed 8 Oct 2017].

8. Nelson JE, Mulkerin CM, Adams LL, et al. Improving comfort and communication in the ICU: a practical new tool for palliative care performance measurement and feedback. Qual Saf Health Care 2006;15:264-71.

9. Institute of Medicine. Crossing the quality chasm: a new health system for the 21st century. The National Academies Sciences Engineering Medicine, 2001. https://doi.org/

10. Azoulay E, Pochard F, Chevret S, et al. Impact of a family information leaflet on effectiveness of information provided to family members of intensive care unit patients: a multicenter, prospective, randomized, controlled trial. Am J Respir Crit Care Med 2002;165:438-42.

11. Lilly CM, De Meo DL, Sonna LA, et al. An intensive communication intervention for the critically ill. Am J Med 2000;109:469-75.

12. Nelson JE, Bassett R, Boss RD, et al. Models for structuring a clinical initiative to enhance palliative care in the intensive care unit: a report from the IPAL-ICU project (improving palliative care in the ICU). Crit Care Med 2010;38:1765-72.

13. Penrod JD, Pronovost PJ, Livote EE, et al. Meeting standards of high-quality intensive care unit palliative care: clinical performance and predictors. Crit Care Med 2012;40:1105-12.

14. Awdish RL, Buick D, Kokas M, et al. A communications bundle to improve satisfaction for critically ill patients and their families: a prospective, cohort pilot study. J Pain Symptom Manage 2017;53:644-9.

15. Gries CJ, Curtis JR, Wall RJ, et al. Family member satisfaction with end-of-life decision making in the ICU. Chest 2008;133:704-12.

16. Huffines M, Johnson KL, Smitz Naranjo LL, et al. Improving family satisfaction and participation in decision making in an intensive care unit. Crit Care Nurse 2013;33:56-69.

17. Sherani K, Shah A, Karki A, et al. Rounding and communication bundle in medical intensive care unit: a quality improvement initiative: identification of barriers. Chest 2016;149:A328.

18. Black MD, Vigorito MC, Curtis JR, et al. A multifaceted intervention to improve compliance with process measures for ICU clinician communication with ICU patients and families. Crit Care Med 2013;41:2275-83.

19. Agency for Healthcare Research and Quality. Highlights from the National healthcare quality and disparities report. Available: https:// archive.ahrq.gov/research/findings/nhqrdr/nhdr10/Key1.html [Accessed 12 Dec 2017].

20. Temel JS, Greer JA, Muzikansky A, et al. Early palliative care for patients with metastatic non-small-cell lung cancer. $N$ Engl J Med 2010;363:733-42.

21. Quill TE, Abernethy AP. Generalist plus specialist palliative care-creating a more sustainable model. N Engl J Med 2013;368:1173-5.

22. Clarke EB, Curtis JR, Luce JM, et al. Quality indicators for end-of-life care in the intensive care unit. Crit Care Med 2003;31:2255-62. 